\title{
A safe method for rapidly achieving plasma concentration plateaus
}

\begin{abstract}
The classical procedure of administering a loading dose as a bolus intravenous injection and at the same time starting an infusion at a constant rate could be dangerous or lead to toxicity with certain drugs. Under such conditions the ratio of the initial plasma concentration $\left(C_{1}^{o}\right)$ to the steady-state plasma concentration $\left(C_{1}^{e q}\right)$ is often large. The higher the ratio of drug in tissues/drug in plasma (i.e., the more "two compartment" the drug is) the higher will be the $C_{1}^{o} / C_{1}^{e q}$ ratio. A method is proposed in which initially a constant-rate infusion at the rate of $Q_{1}$ is given over $T$ hours $(0.25$ to 3 $h r)$; then the rate is abruptly changed to a lower rate $Q_{2}$, which is maintained as long as steady state is desired. A simple relationship is given that shows what the ratio of $Q_{1} / Q_{2}$ must be to attain steady state most rapidly and to minimize the ratio $C_{1}^{M A X} / C_{1}^{e q}$, where $C_{1}^{M A X}$ is the maximum plasma concentration attained at time $T$, just as the infusion at the higher rate ceases. A simple linear graph is given that allows rapid determination of the needed ratio $Q_{1} / Q_{2}$. Variables needed for a given drug to use the method are plasma clearance and plasma half-life.
\end{abstract}

John G. Wagner, Ph.D. Ann Arbor, Mich.

The College of Pharmacy and Upiohn Center for Clinical Pharmacology, The University of Michigan

The accumulation of a drug in the human body during a constant-rate intravenous infusion was first treated mathematically by Widmark and Tandberg, ${ }^{6}$ based on the one-compartment open model. Based on this analysis, the loading dose (units of mass) needed to rapidly attain the steady state is equal to the infusion rate

Supported in part by United States Public Health Service Grant No. 5-P11-GM15559.

Received for publication Jan. 24, 1974.

Accepted for publication May 8, 1974.

Reprint requests to: Dr. John G. Wagner, Upjohn Center for Clinical Pharmacology, the University of Michigan, Ann Arbor, Mich. 48105. (units of mass/time) divided by the elimination rate constant (units of $1 /$ time). The elimination rate constant is equal to the natural logarithm of 2 (namely, 0.693) divided by the half-life of the drug. The theory, based on this one-compartment analysis, indicates that if one administers this loading dose by rapid intravenous injection and, at the same time, starts a constant-rate infusion, a steady state will be "instantaneously" established and the plasma concentration of drug would be the same from time zero to the time the infusion ceases. 


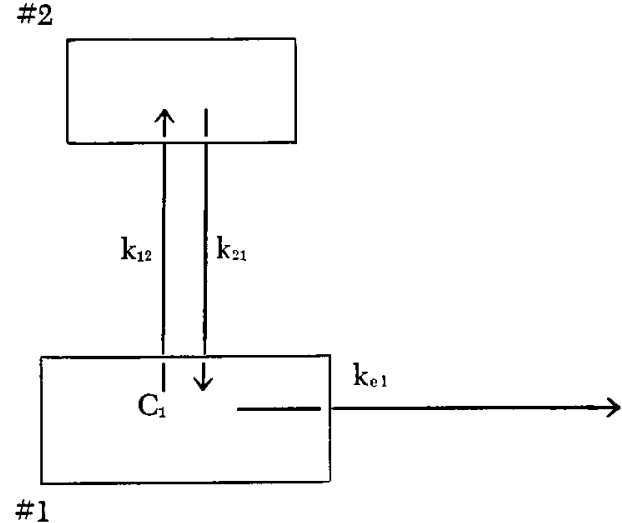

Schema I.

It is desirable to rapidly attain steady state in many pharmacokinetic studies, such as renal clearance studies, as well as in the therapy of certain diseases where the site action of the drug is in the central (plasma) compartment. Using the preceding conditions, many clinicians appear to be unaware that the initial plasma concentration at time zero (just after injection of the loading dose) can be very much higher than the final steady-state plasma concentration, since, frequently, the first blood sample is not taken until an hour or more after injection of the loading dose and the start of the intravenous infusion, while the drug obeys the two-compartment rather than the one-compartment open model.

Most drugs really do not obey the onecompartment model, but rather the twocompartment open model, depicted in Schema I. In this model $k_{12}$ and $k_{21}$ are firstorder distribution rate constants and $k_{\mathrm{el}}$ is the first-order elimination rate constant. The plasma concentration is taken as representative of the concentration, $\mathrm{C}_{1}$, in compartment No. 1 (also called the "central" compartment) at time $t$ after administration. When a drug obeys this model the apparent elimination rate constant, $\beta$, obtained from terminal plasma concentration data, is a complex function of $k_{12}, k_{21}$, and $\mathrm{k}_{\mathrm{el}}$; the half-life of elimination, obtained from plasma concentration data, is $t_{1 / 2}=0.693 / \beta$.
During the past decade the parameters $k_{12}, k_{21}, k_{e l}$, and $V_{1}$ of the model shown in Schema I have been published for many drugs. This report shows how a given set of parameters for a given subject or animal and for a given drug may be used to calculate two successive infusion rates that provide rapid attainment of steady-state plasma levels and the maximum plasma concentration attained at the end of the initial infusion at the faster rate. Although most useful for pharmacokinetic studies, the method may find some application in therapy of certain diseases also.

\section{Experimental and results}

Conceptual infusion at one rate only. If a constant-rate infusion is given without a loading dose it takes a long time to approach steady state. This is indicated by Fig. 1, which shows the time-course for the first 10 hours for theophylline, based on the average values of the parameters of 3 subjects published by Mitenko and Ogilvie. ${ }^{3}$ The simulation is based on a steady-state plasma concentration of 10 $\mu \mathrm{g} / \mathrm{ml}$. In this case it would require 18.77 hours (equivalent to 4.26 half-life periods of theophylline) to reach $95 \%$ of the steady-state value (i.e., $9.5 \mu \mathrm{g} / \mathrm{ml}$ ) and 9.94 hours (equivalent to 2.25 half-life periods) to reach $80 \%$ of the steady-state value (i.e., $8.0 \mu \mathrm{g} / \mathrm{ml}$ ). For drugs with half-lives that are greater than about $0.5 \mathrm{hr}$., the single-infusion method is not very practical.

Infusion plus loading dose. For the model shown in Schema $I$, the relative values of the loading dose $(R)$ and the infusion rate $(Q)$ are critical in determining the time-course of plasma concentrations. Boyes and associates ${ }^{1}$ recommended that the relationship should be $\mathrm{R}=\mathrm{Q} / \mathrm{k}_{\mathrm{el}}$. Mitenko and Ogilvie recommended that the relationship should be $R=Q / \beta$. The simulations shown in Fig. 2 are typical of the results that would be achieved with theophylline with these recommendations. When $\mathbf{R}=\mathrm{Q} / \mathrm{k}_{\mathrm{el}}$ then at $\mathrm{t}=0, \mathrm{C}_{1}^{0}=10$ $\mu \mathrm{g} / \mathrm{ml}$, but the plasma concentration then 


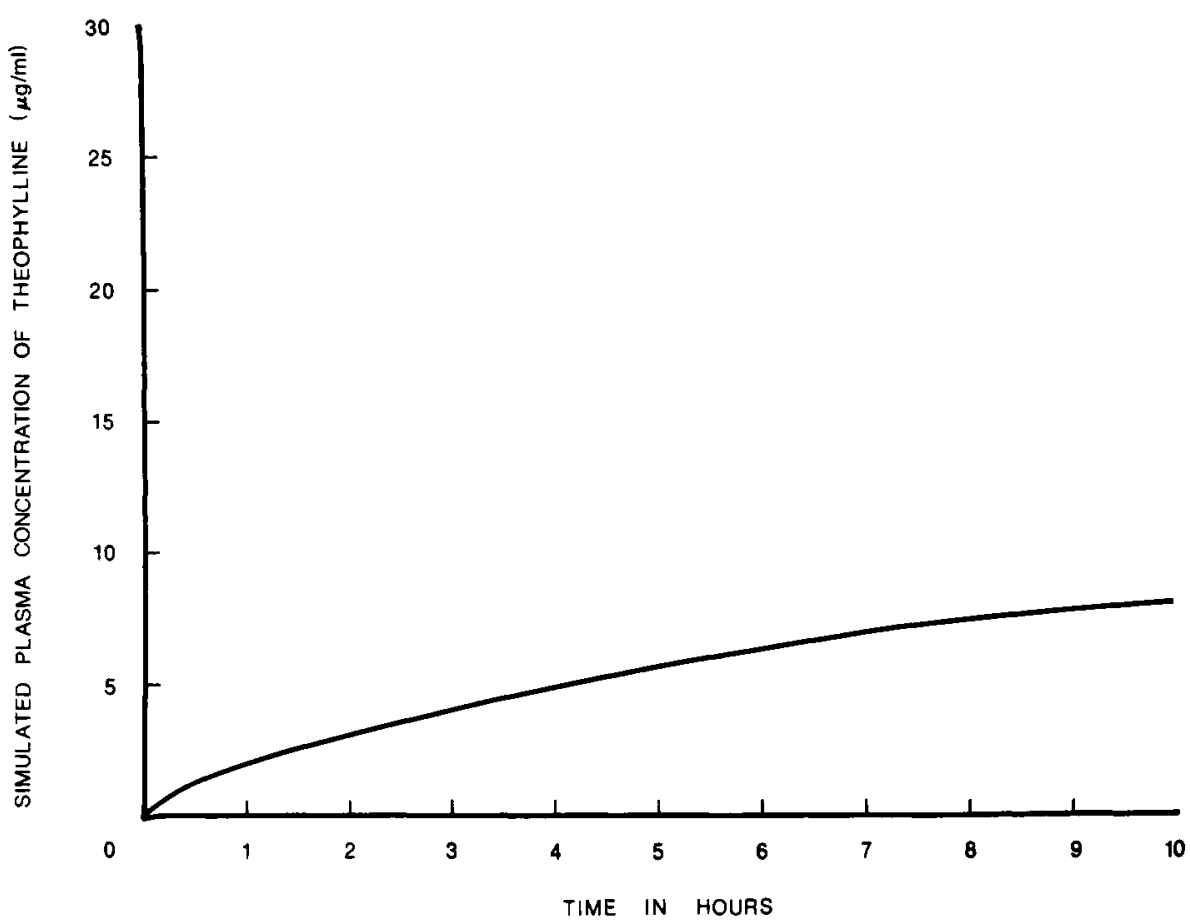

Fig. 1. Time-course of simulated theophylline plasma concentrations with infusion rate of $0.656 \mathrm{mg} / \mathrm{kg} / \mathrm{hr}$. Curve is based on Equations 1 and 2 of the Appendix, using average values of the parameters of three subjects, namely $\alpha=6.36 \mathrm{hr}^{-1} \beta=0.157 \mathrm{hr}^{-1} \mathrm{k}_{21}=$ $2.16 \mathrm{hr},{ }^{-1} \mathrm{~V}_{1}=0.142 \mathrm{ml} / \mathrm{kg}$, published by Mitenko and Ogilvie. ${ }^{3}$ Calculation was made for $\mathrm{C}_{1}^{\mathrm{eq}}=10 \mu \mathrm{g} / \mathrm{ml}$.

drops, reaches a minimum, then slowly rises and approaches the equilibrium concentration of $10 \mu \mathrm{g} / \mathrm{ml}$ again. When $\mathrm{R}=\mathrm{Q} / \beta$, then at $\mathrm{t}=0, \mathrm{C}_{1}^{\mathrm{o}}=29.4 \mu \mathrm{g} / \mathrm{ml}$ and the plasma concentration drops rapidly and within about 1 hour is essentially equal to the steady-state concentration of $10 \mu \mathrm{g} / \mathrm{ml}$. The ratio of the initial concentration $\left(\mathrm{C}_{1}^{0}\right)$ to the equilibrium concentration $\left(\mathrm{C}_{1}^{\mathrm{eq}}\right)$ is equal to $\mathrm{k}_{\mathrm{cl}} / \beta$. The inverse ratio, $\beta / \mathrm{k}_{\mathrm{cl}}$, indicates how "two compartment" a particular drug is. The smaller this ratio the greater the amount of drug in compartment No. 2 compared with the amount in compartment No. 1 at any time (Schema I). The influence of this ratio on the ratio of $\mathrm{C}_{1}^{0} /$ $\mathrm{C}_{1}^{\mathrm{eq}}$ is shown in Fig. 3. Krüger-Thiemer, ${ }^{2}$ recommended administering the loading dose, then a continuous infusion, the rate of which decreases exponentially to the proper steady-state rate, but this is more difficult than the new method proposed:
Two consecutive infusions. A new method is described below in which an initial constant-rate infusion is given at a rate $Q_{1}$ over $T$ hours. At the end of $T$ hours the infusion rate is abruptly changed to a lower rate $Q$. which is maintained as long as a steady-state plasma concentration is desired.

A critical ratio of $Q_{1} / Q_{2}$ has been determined (Equation 8, Appendix), which provides the most rapid attainment of the steady state. The steps required to apply the method are indicated below (see also Table I):

1. Choose the equilibrium state plasma level desired (i.e., choose $\mathrm{C}_{1}^{\mathrm{eq}}$ ).

2. Calculate the final infusion rate as follows:

$$
\mathrm{Q}_{2}=\text { Plasma clearance } \times \mathrm{C}_{1}^{\mathrm{eq}} \text {. }
$$

3. Choose the time $T$ over which to administer the initial infusion at the rate $Q_{1}$. 


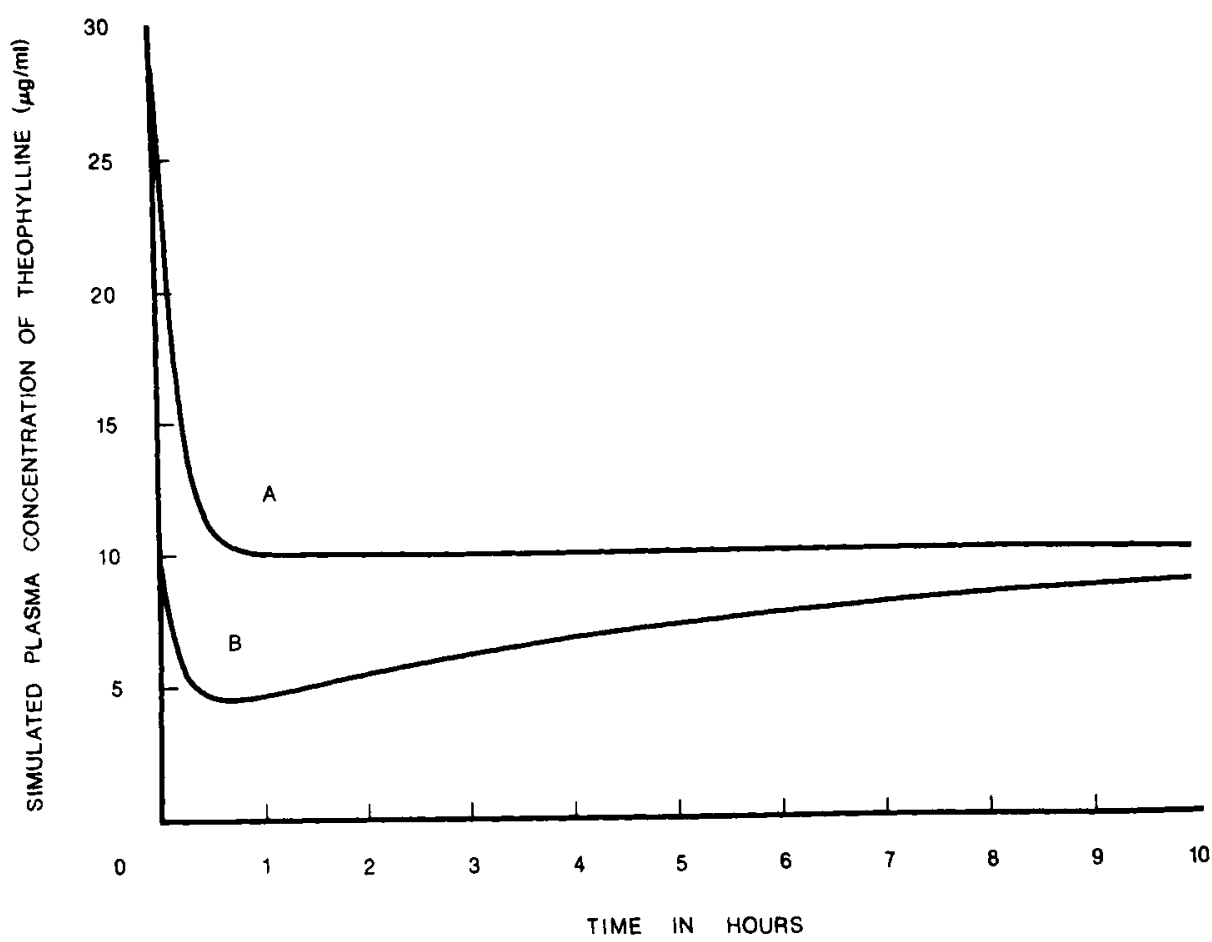

Fig. 2. Time-course of simulated theophylline plasma concentrations, based on same parameters as in Fig. 1. Curve $A$ is for recommendation of Mitenko and Ogilvie where $\mathrm{R}=\mathrm{Q} / \beta$. Curve $B$ is for recommendation of Boyes and associates ${ }^{1}$ where $R=Q / k_{\mathrm{e}}$. In both cases $\mathrm{Q}=0.656 \mathrm{mg} / \mathrm{kg} / \mathrm{hr}$ and $\mathrm{C}_{1}^{\mathrm{eq}}=10 \mu \mathrm{g} / \mathrm{ml}$.

This often can be $0.25 \mathrm{hr}(15 \mathrm{~min})$, but with some toxic drugs should be as long as 3 or 4 hours. Fig. 6 and Equation 18 aid in the choice of T.

4. Calculate the ratio of the half-life of the drug $\left(t_{1 / 2}\right)$ to the chosen time $T$ (i.e., $t_{1 / 2} / T$ ).

5. Use the graph in Fig. 4 for this value of $t_{1 / 2} / T$ to find the ratio $Q_{1} / Q_{2}$.

6. Since you know $Q_{2}$ you can now calculate $Q_{1}$ since $Q_{1}=\left(Q_{1} / Q_{2}\right)\left(Q_{2}\right)$.

The above procedure is accurate as long at $t_{1 / 2} / T$ is equal to or greater than 6.93. Whenever the ratio $t_{z_{2} / T} / T$ is less than 6.93 then $Q_{1}$ should be calculated by means of Equation 7 (Appendix).

Fig. 5 illustrates the results to be achieved with this method with theophylline and a comparison is made of the results that would be obtained by the method of Mitenko and Ogilvie. ${ }^{4}$ For this simulation the average parameter values of theo- phylline, given by Mitenko and Ogilvie, ${ }^{4}$ for 7 asthmatic patients were used. These values were $\alpha=5.99 \mathrm{hr}^{-1}, \beta=0.162 \mathrm{hr}^{-1}$, $\mathrm{k}_{\mathrm{el}}=0.312 \mathrm{hr}^{-1}$, and $\mathrm{V}_{1}=0.277 \mathrm{l} / \mathrm{kg}$. From these one can calculate $k_{12}=2.73$ $\mathrm{hr}^{-1}$ and $\mathrm{k}_{21}=3.11 \mathrm{hr}^{-1}$. The simulation is based on choosing $\mathrm{C}_{1}^{\mathrm{eq}_{1}}=10 \mu \mathrm{g} / \mathrm{ml}$ and $\mathrm{T}=0.5 \mathrm{hr}$. The steps for this example, corresponding to steps 1 to 6 above, are as follows:

$$
\begin{aligned}
& \text { 1. } \mathrm{C}_{1}^{\mathrm{eq}}=10 \mu \mathrm{g} / \mathrm{ml} . \\
& \text { 2. } \mathrm{Q}_{2}=V_{1} \mathrm{k}_{\mathrm{e} 1} \mathrm{C}_{1}^{\mathrm{eq}}=(0.277) \quad(0.312) \\
& \begin{array}{l}
\text { (10) }=0.864 \mathrm{mg} / \mathrm{kg} / \mathrm{hr} . \\
\text { 3. } \mathrm{T}=0.5 \mathrm{hr} . \\
\text { 4. } \mathrm{t}_{1 / 2}=0.693 / \beta=0.693 / 0.162=4.28 \mathrm{hr}
\end{array}
\end{aligned}
$$
and $t_{1 / 2} / T=4.28 / 0.5=8.56$.

5. Using Fig. 4 one finds $\mathrm{Q}_{1} / \mathrm{Q}_{2}=12.8$ corresponding to $t_{1 / 2} / T=8.56$.

6. Hence, $Q_{1}=(12.8)(0.864)=11.1$ $\mathrm{mg} / \mathrm{kg} / \mathrm{hr}$.

It should be noted that the curves shown in Figs. 2 and 5 for the Mitenko-Ogilvie 


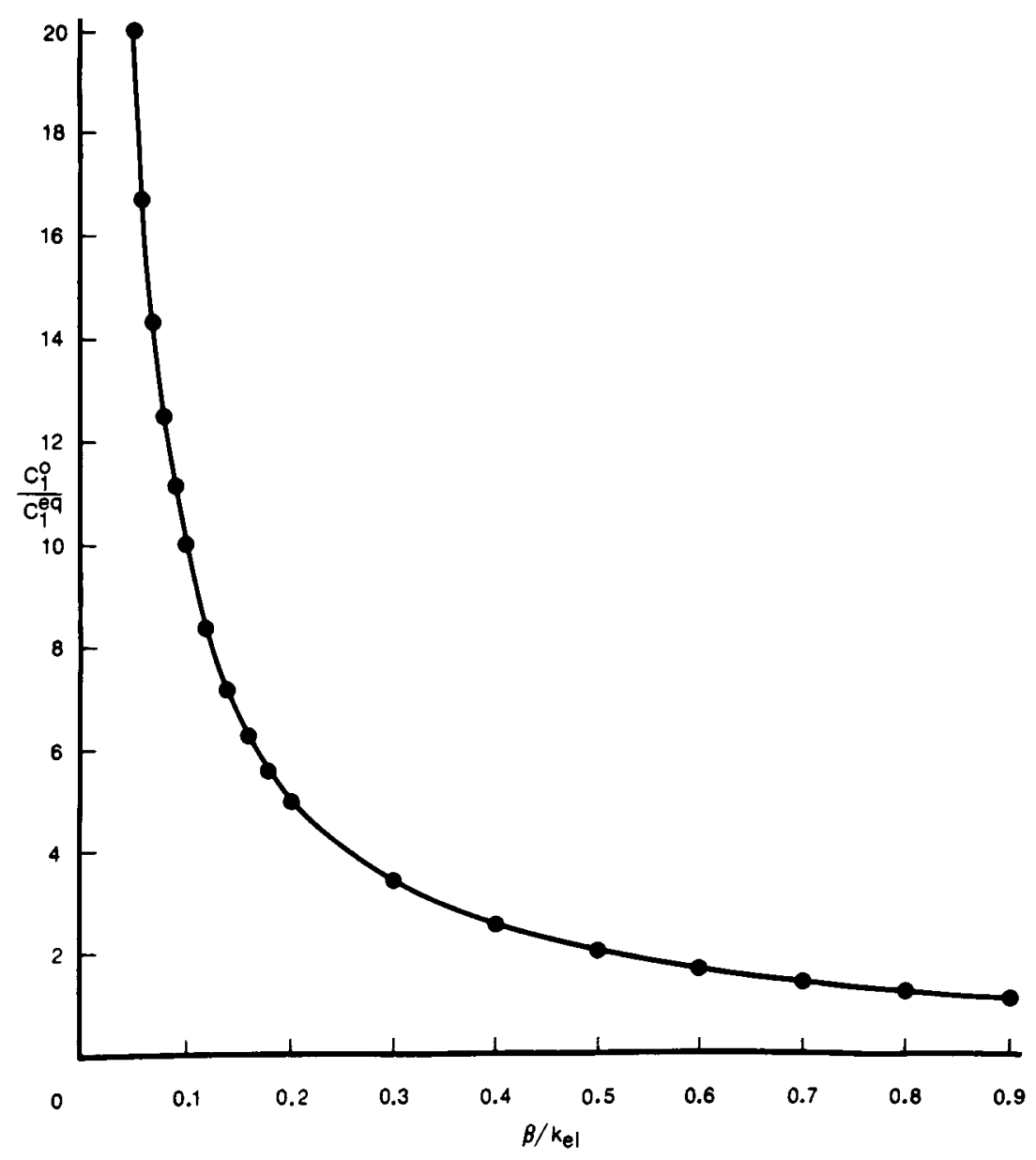

Fig. 3. Relationship between the ratio of the initial plasma concentration to the equilibrium plasma concentration $\left(\mathrm{C}_{1}^{\circ} / \mathrm{C}_{1}^{\mathrm{eq}}\right)$ and the ratio $\beta / \mathrm{k}_{\mathrm{r} 1}$.

Table I. Data used to prepare the approximate plot of $Q_{1} / Q_{2}$ vs $t_{1 / 2} / T$ shown in Fig. 4

\begin{tabular}{|c|c|c|c|c|c|}
\hline $\begin{array}{c}\text { Col. } 1 \\
t_{1 / 2} / T\end{array}$ & $\begin{array}{l}\text { Col. } 2 \\
\beta T\end{array}$ & $\begin{array}{l}\text { Col. } 3 \\
1 / \beta T\end{array}$ & $\begin{array}{c}\text { Col. } 4 \\
\frac{Q_{1}}{Q_{s}}=1 /\left(1-e^{-\beta T}\right)\end{array}$ & $\begin{array}{c}\text { Col. } 5 \\
0.5+1.443\left(t_{1 / 2} / T\right)^{*}\end{array}$ & $\begin{array}{l}\text { Col. } 6 \\
\% \text { error }\end{array}$ \\
\hline 90 & 0.0077 & 129.9 & 130.4 & 130.4 & 0 \\
\hline 32 & 0.02166 & 46.18 & 46.68 & 46.68 & 0 \\
\hline 30 & 0.0231 & 43.25 & 43.79 & 43.79 & 0 \\
\hline 15 & 0.0462 & 21.65 & 22.15 & 22.15 & 0 \\
\hline 10 & 0.0693 & 14.43 & 14.93 & 14.93 & 0 \\
\hline 6.93 & 0.1000 & 10.00 & 10.508 & 10.50 & -0.08 \\
\hline 5 & 0.1386 & 7.216 & 7.727 & 7.715 & -0.16 \\
\hline 3 & 0.23105 & 4.328 & 4.847 & 4.829 & -0.37 \\
\hline 2.079 & 0.3333 & 3.000 & 3.528 & 3.500 & -0.79 \\
\hline 0.693 & 1.0000 & 1.000 & 1.582 & 1.500 & -5.18 \\
\hline 0.50 & 1.386 & 0.7215 & 1.3335 & 1.222 & -8.36 \\
\hline 0.3465 & 2.000 & 0.5000 & 1.157 & 1.000 & -15.7 \\
\hline
\end{tabular}

${ }^{\circ}$ For the first six values of Cols. 1 and 4 , least-squares linear regression gave the equation $Q_{1} / Q_{2}=0.50+1.443\left(t^{2} / 2 / T\right)$ with a correlation coefficient equal to 1.00000 . The estimated values from this equation are shown in Col. 5 . The error of the value in Col. 5 from the actual value in Col. 4 is shown in Col. 6. For values of $t_{i / 2} / T$ less than 6.93 (shown in the lower half of the table), one should use the exact relationship given in Col. 4. 


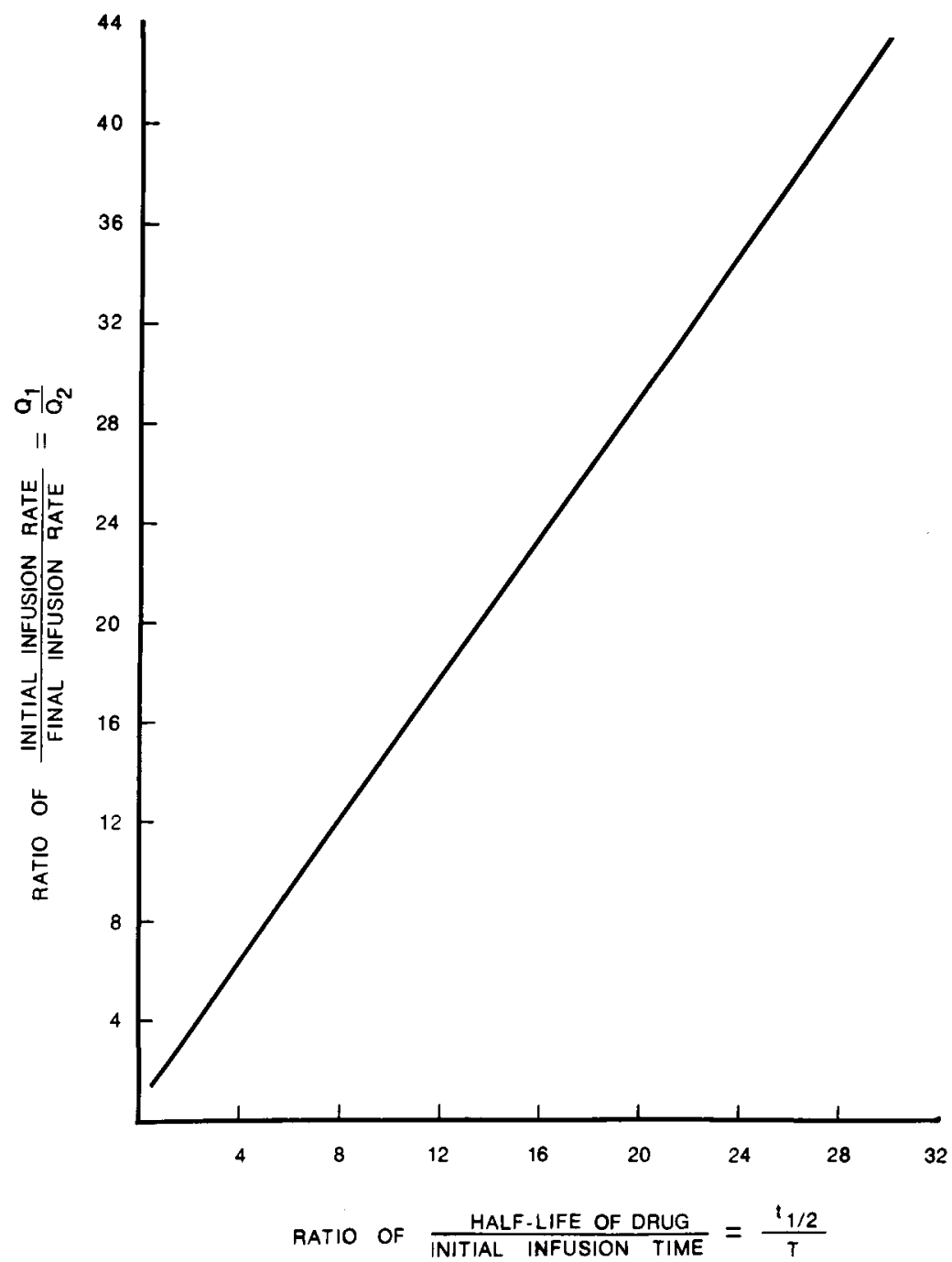

Fig. 4. Convenient way to estimate the ratio of the initial infusion rate to the final infusion rate $\left(Q_{1} / Q_{2}\right)$ from the ratio of the half-life of the drug to the duration of the initial infusion $\left(t_{1 / 2} / T\right)$. The line is based on the equation: $Q_{1} / Q_{2}=0.50+1.443 t_{1 / 2} / T$ and its source is explained in Table I.

method $^{3}$ are very similar to real plasma concentration, time curves of theophylline published by these authors, except here $\mathrm{C}_{1}^{\mathrm{eq}}=10 \mu \mathrm{g} / \mathrm{ml}$, whereas in their article $\mathrm{C}_{1}^{\mathrm{eq}}=5 \mu \mathrm{g} / \mathrm{ml}$.

\section{Discussion}

If we let $\mathrm{C}_{1}^{\mathrm{MAX}}$ be the maximum plasma concentration at time $\mathrm{T}$ just when the infusion rates are changed in the proposed method (peak in Fig. 5 at $0.5 \mathrm{hr}$ ), then in this simulation $\mathrm{C}_{1}^{\mathrm{MAX}}=12.9 \mu \mathrm{g} / \mathrm{ml}$, corresponding to $\mathrm{C}_{1}^{0}=19.3 \mu \mathrm{g} / \mathrm{ml}$ with the Ogilvie-Mitenko method. However, if $\mathrm{T}$ had been made longer ( 1 or $2 \mathrm{hr}$ ) then $\mathrm{C}_{1}^{\mathrm{MAx}}$ would have been much smaller. This is the advantage of the proposed method. One can set the ratio of $\mathrm{C}_{1}^{\mathrm{MAx}} / \mathrm{C}_{1}^{\text {eq }}$ to any desired value by adjusting the time $\mathrm{T}$ of the initial infusion. Once the final infusion is started, the time required to reach the steady-state plasma concentration is based 


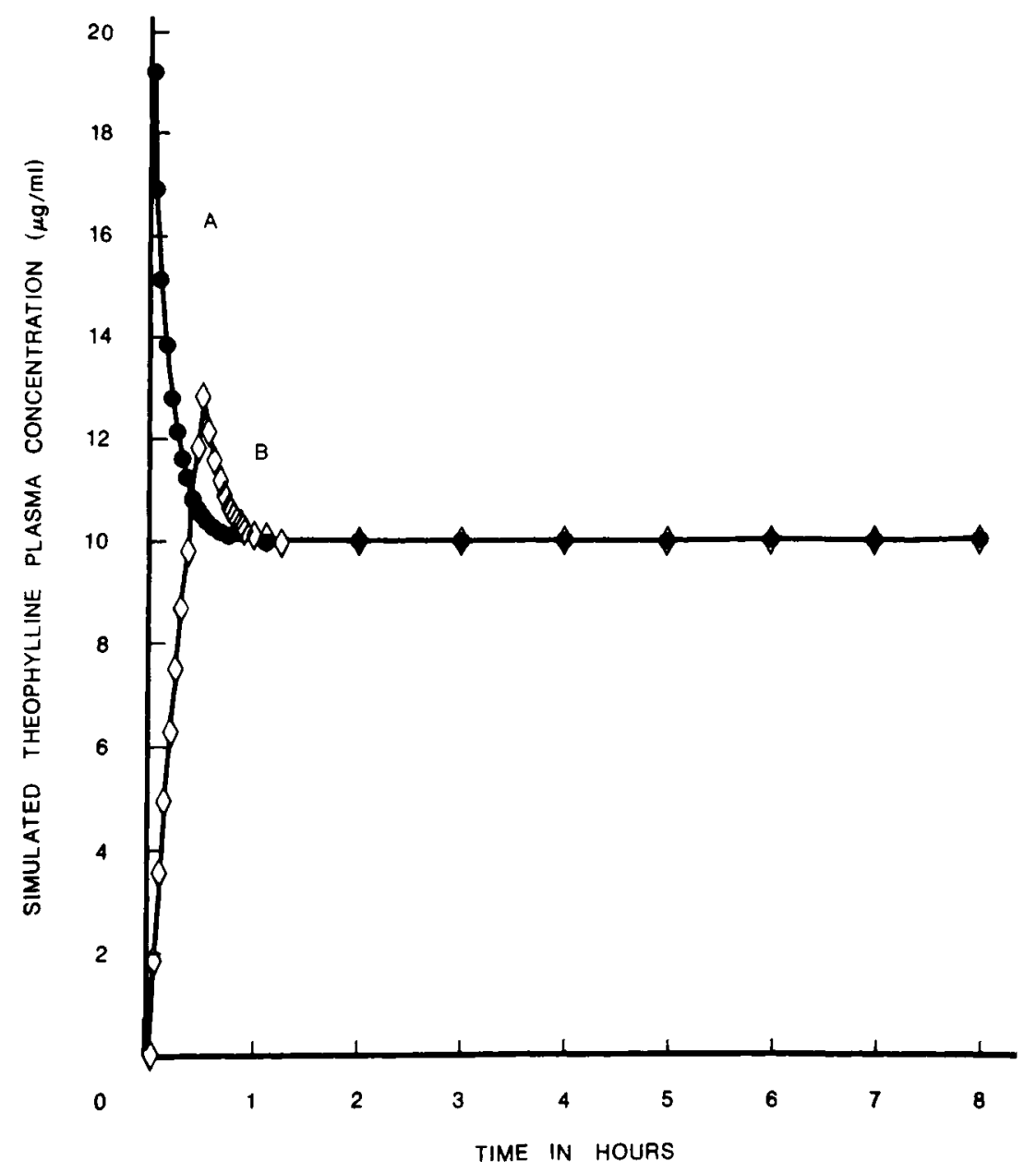

Fig. 5. Comparison of results to be achieved with proposed method (curve $B$ ) compared with results achieved with method of Mitenko and Ogilvie. ${ }^{4}$ Parameters used were the averages for 7 asthmatic patients published by Mitenko and Ogilvie, ${ }^{+}$namely $\alpha=5.99 \mathrm{hr},{ }^{-1} \beta=$ $0.162 \mathrm{hr},{ }^{-1} \mathrm{k}_{11}=0.312 \mathrm{hr},{ }^{-1}$ and $\mathrm{V}_{\mathrm{x}}=0.277 \mathrm{l} / \mathrm{kg}$.

only on the value of $\mathrm{e}^{-\alpha t}$ as in the MitenkoOgilvie $^{4}$ method. Since $\alpha$ is usually quite large, then $\mathrm{e}^{-\alpha \mathrm{t}}$ approaches zero rapidly and the fall from $\mathrm{C}_{1}^{\mathrm{MAX}}$ to $\mathrm{C}_{1}^{\mathrm{eq}}$ is rapid, as Fig. 5 illustrates.

In the Mitenko-Ogilvie ${ }^{4}$ method, the ratio of $\mathrm{C}_{1}^{0} / \mathrm{C}_{1}^{\prime \mathrm{c}}$ is equal to $\mathrm{k}_{\mathrm{el}} / \beta$. When a drug nearly obeys the one-compartment open model then $\beta \simeq \mathrm{k}_{\mathrm{+} 1}$ and $\mathrm{C}_{1}^{0} / \mathrm{C}_{1}^{+1} \simeq 1$, but most drugs really obey the two-compartment open model and frequently $\mathrm{k}_{\mathrm{el}} / \beta$ ranges from about 1.6 to 5 . Hence $C_{1}^{0} / C_{1}$ ranges from 1.6 to 5 . Such high initial plasma concentrations can lead to toxicity, particularly with drugs with a narrow range between the toxic and therapeutic doses and plasma levels. I suggest that the proposed consecutive infusion method is a much safer procedure.

Harvard infusion pumps have different settings and with this type of pump it is easy to give an initial infusion at one rate and abruptly change to a lower rate simply by dialing to a new setting. If a drop apparatus is used, one could determine the drop rate to provide the two rates $Q_{1}$ and $Q_{2}$ and predetermine the clamp settings needed to provide the two drop rates. 

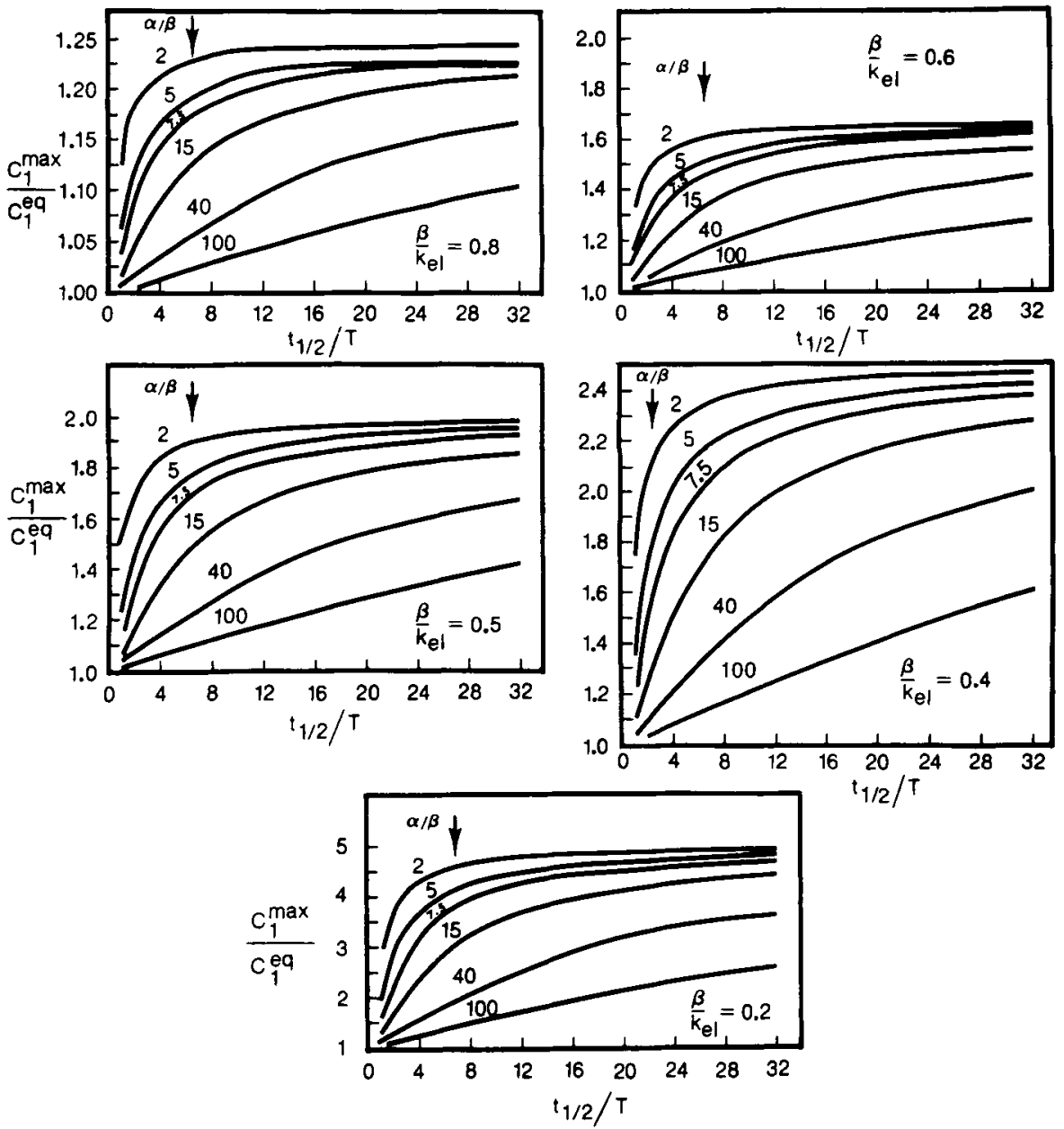

Fig. 6. Plots of the ratio $C_{1}^{M A x} / C_{1}^{e q}$ vs $t_{1 / 2} / T$ for various values of $\alpha / \beta$ and $\beta / k_{01}$. The plots were obtained by use of Equation 18 .

\section{References}

1. Boyes, R. N., Scott, D. B., Jebson, R. J., Godman, M. J., and Julian, D. G.: Pharmacokinetics of lidocaine in man, Clin. Pharmacol. Ther. 12:105-115, 1971.

2. Krüger-Thiemer, E.: Continuous intravenous infusion and multicompartment accumulation, Eur. J. Pharmacol. 4:317-324, 1968.

3. Mitenko, P. A., and Ogilvie, R. I.: Rapidly achieved plasma concentration plateaus, with observations on theophylline kinetics, CLIN. Pharmacol. Ther. 13:329-335, 1972.
4. Mitenko, P. A., and Ogilvie, R. I.: Pharmacokinetics of intravenous theophylline, Clin. PHarMaCOL. Ther. 14:509-513, 1973.

5. Wagner, J. G.: Biopharmaceutics and relevant pharmacokinetics, Hamilton, Ill., 1971, Drug Intelligence Publications, p. 255.

6. Widmark, E., and Tandberg, J.: Über die Bedingungen für die Akkumulation Indifferenter Narkotika. Theoretische Berechnunger, Biochem. Z. 147:358-369, 1924.

\section{Appendix}

Constant rate infusion only at one rate. If a single infusion is given at the rate $Q$ (units of mass/time) without a loading dose, then the concentration in the central compartment (equivalent to the plasma concentration) is given by Equation 1, 


$$
\mathrm{C}_{1}=\mathrm{C}_{1}^{\mathrm{eq}}\left[1-\left(\frac{\mathrm{k}_{\mathrm{e} 1}-\beta}{\alpha-\beta}\right) \mathrm{e}^{-\alpha^{\mathrm{t}}}-\left(\frac{\left(\alpha-\mathrm{k}_{\mathrm{e} 1}\right)}{\alpha-\beta}\right) \mathrm{e}^{-\beta^{\mathrm{t}}}\right]
$$

where

$$
\mathrm{C}_{1}^{\mathrm{eq}}=\mathrm{Q} / \mathrm{V}_{\mathbf{1}} \mathrm{k}_{\mathrm{e}}
$$

and $\alpha$ and $\beta$ are defined by Wagner ${ }^{5}$ and many other authors.

Two consecutive infusions. In this method an initial infusion is given at the rate $Q_{1}$ over $\mathrm{T}$ hours (i.e., in the interval $0 \leq t \leq T$ ). At time $\mathrm{T}$ the infusion rate is abruptly changed to the lower rate $Q_{2}=V_{1} k_{e_{1}} C_{1}^{e q}$ (i.e., for $t \geq T$ ).

The concentration during the interval $0 \leq \mathrm{t} \leq \mathrm{T}$ will be given by Equations 1 and 2 where $Q$ replaces $Q$ in Equation 2.

The concentration during the second infusion will be given by Equations 3, 4, and 5,

$$
\begin{aligned}
C_{1} & =C_{1}^{\mathrm{eq}}+\left\{\frac{\left(k_{21}-\alpha\right)\left(Q_{2}-\alpha A_{1}^{T}\right)-\alpha k_{21} A_{2}^{T}}{\alpha(\alpha-\beta) V_{1}}\right\} e^{-\alpha(t-T)} \\
& -\left\{\frac{\left(k_{21}-\beta\right)\left(Q_{2}-\beta A_{1}^{T}\right)-\beta k_{21} A_{2}^{T}}{\beta(\alpha-\beta) V_{1}}\right\} e^{-\beta(t-T)}
\end{aligned}
$$

where

$$
\begin{aligned}
& A_{1}^{T}=\frac{Q_{1}}{k_{\mathrm{e} 1}}+\left\{\frac{Q_{1}\left(k_{21}-\alpha\right)}{\alpha(\alpha-\beta)}\right\} e^{-\alpha^{T}}-\left\{\frac{Q_{1}\left(k_{21}-\beta\right)}{\beta(\alpha-\beta)}\right\} e^{-\beta^{T}} \\
& A_{2}^{T}=\frac{k_{12} Q_{1}}{k_{21} k_{\mathrm{el}}}+\left\{\frac{k_{12} Q_{1}}{\alpha(\alpha-\beta)}\right\} e^{-\alpha^{T}}-\left\{\frac{k_{12} Q_{1}}{\beta(\alpha-\beta)}\right\} e^{-\beta^{T}} .
\end{aligned}
$$

For $C_{1}$ to be always greater than or equal to $C_{1}^{e q}$ during the second infusion requires that the coefficient of the third term of Equation 3 (i.e., the coefficient of the $e^{-\beta(t-T)}$ term) be equal to zero. Equating the numerator of this term to zero gives Equation 6,

$$
\beta \mathrm{k}_{21} \mathrm{~A}_{2}^{\mathrm{T}}-\left(\mathrm{k}_{21}-\beta\right)\left(\mathrm{Q}_{2}-\beta \mathrm{A}_{1}^{\mathrm{T}}\right)=0 .
$$

Substituting from Equations 4 and 5 into Equation 6 and simplifying gives Equation 7,

$$
\mathrm{Q}_{1}=\mathrm{Q}_{\mathbf{2}} /\left(1-\mathrm{e}^{-\beta \mathrm{T}}\right) \text {. }
$$

Hence the concentration $C_{1}$ during the second infusion will always be greater than or equal to $\mathrm{C}_{1}^{\mathrm{eq}}$. when the ratio of the infusion rates is given by

$$
\mathrm{Q}_{1} / \mathrm{Q}_{2}=1 /\left(1-\mathrm{e}^{-\beta \mathrm{T}}\right) \text {. }
$$

If a single bolus intravenous injection of a drug is administered, then the plasma concentration, time curve can usually be fitted to Equation 9 ,

$$
\mathrm{C}_{1}=A \mathrm{e}^{-\alpha^{\mathrm{t}}}+\mathrm{Be}^{-\beta \mathrm{t}} \text {. }
$$

The plasma clearance is the ratio of the dose (D) divided by the total area under the concentration, time curve as indicated by Equation 10,

$$
\mathrm{V}_{\mathrm{l}} \mathrm{k}_{\mathrm{e} 1}=\frac{\mathrm{D}\left(\mathrm{I} . \mathrm{V}_{\mathrm{S}}\right)}{\frac{\mathrm{A}}{\alpha}+\frac{\mathrm{B}}{\beta}}
$$

The final infusion rate, $Q_{2}$, is then calculated by Equation 11,

$$
\mathrm{Q}_{2}=\mathrm{V}_{1} \mathrm{k}_{\mathrm{e}} \mathrm{C}_{1}^{\mathrm{eq}}=(\text { Plasma clearance })\left(\mathrm{C}_{1}^{\mathrm{eq}}\right) \text {. }
$$

Once $C_{1}^{\mathrm{eq}}$ is chosen, one calculates $Q_{2}$ with Equation 11. One then chooses some convenient time $T$ for the first infusion and calculates the initial infusion rate $Q_{1}$ with Equation 7 .

Simplified method to calculate the ratio of infusion rates, $Q_{1} / Q_{2}$. The expansion of $\mathrm{e}^{-\mathrm{x}}$ is given by Equation 12, 


$$
e^{-x}=1-x+\frac{x^{2}}{2}-\frac{x^{3}}{6}+\ldots
$$

When $x \geq 0.1$ then

$$
\mathrm{e}^{-\mathbf{x}} \simeq 1-\mathrm{x}
$$

Substituting $\beta \mathrm{T}$ for $\mathrm{x}$ in Equation 13 gives after rearrangement

$$
1-\mathrm{e}^{-\beta \mathrm{T}} \simeq \beta \mathrm{T} \text {. }
$$

Substituting from Equation 14 and for $\beta$ into Equation 8 gives:

$$
\mathrm{Q}_{1} / \mathrm{Q}_{2}=1.443\left(\mathrm{t}_{1 / 2} / \mathrm{T}\right) \text {. }
$$

Relationship between proposed method and method of Mitenko and Ogilvie. Substituting from Equation 14 into Equation 8 gives

$$
Q_{1} / Q_{2} \simeq 1 / \beta T \text {. }
$$

Rearrangement of Equation 16 gives

$$
\mathrm{Q}_{1} \mathrm{~T} \simeq \mathrm{Q}_{2} / \beta .
$$

Since $Q_{T} T$ is equal to the mass of drug administered as the initial infusion over the time zero to $T$ hours, this is analogous to the Mitenko and Ogilvie loading dose $R$. The relationship necessary to produce the Mitenko and Ogilvie result is $\mathrm{R}=\mathrm{Q} / \beta$. Hence the similarity between the two methods is obvious.

Estimation of $\mathrm{C}_{1}^{\mathrm{MAX}}$ and guidelines to choice of the time $T$. As indicated formerly, in application of the proposed method the maximum plasma concentration, $\mathrm{C}_{1}^{\mathrm{MAX}}$, is reached at time $T$ corresponding to the end of the infusion at the rate $Q_{1}$. By letting $\beta=0.693 / \mathrm{t}_{1 / 6}$ and $\mathrm{r}=\alpha / \beta$ and using Equations 1 and 8, one can derive Equation 18,

$$
\frac{\mathrm{C}_{1}^{\mathrm{MAX}}}{\mathrm{C}_{1}^{\mathrm{eq}}}=\frac{1}{1-\mathrm{e}^{-0.693 \mathrm{~T} / \mathrm{t} 1 / 2}}\left[1-\left(\frac{\left(\mathrm{k}_{\mathrm{e} 1} / \beta\right)-1}{\mathrm{r}-\mathrm{l}}\right)^{-0.693 \mathrm{~T} / \mathrm{t} 1 / \mathrm{s}}-\left(\frac{\mathrm{r}-\left(\mathrm{k}_{\mathrm{e} 1} / \beta\right)}{\mathrm{r}-1}\right)^{-0.693 \mathrm{~T} / \mathrm{t} / 2}\right] .
$$

Equation 18 indicates that the ratio $\mathrm{C}_{1}^{\mathrm{MAX}} / \mathrm{C}_{1}^{\mathrm{eq}}$ is a complex, nonlinear function of the ratios $\alpha / \beta, \beta / \mathrm{k}_{\mathrm{e} 1}$, and $\mathrm{t}_{1 / 2} / \mathrm{T}$. Fig. 6 shows representative data obtained with Equation 18 . It should be noted that the ordinate scales of each of the small figures are different to facilitate reading the graphs. If one knows the values of $\alpha / \beta, \beta / \mathrm{k}_{\mathrm{el}}$, and $\mathrm{t}_{1 / 2}$, one can obtain an exact value of $\mathrm{C}_{1}^{\mathrm{MAX}} / \mathrm{C}_{1}^{\mathrm{eq}}$ for a given value of $\mathrm{T}$ by use of Equation 18 . However, useful approximations may be made from the graphs in Fig. 6. For the example given in the text and Fig. $5, \alpha / \beta=36.9, \beta / \mathrm{k}_{\mathrm{v} 1}=0.52, \mathrm{t}_{1 / 2}=4.28$, and when $\mathrm{T}=0.5$, then $\mathrm{t}_{1 / 2} / \mathrm{T}=8.56$. Using the graph in Fig. 6 for $\beta / k_{11}=0.5$ and $\alpha / \beta=40$, one estimates $\mathrm{C}_{1}^{\mathrm{MAX}} / \mathrm{C}_{1}^{\mathrm{eq}} \simeq 1.3$ for $t_{1 / 2} / T=8.6$. The actual value is 1.29 rather than 1.3. In general the graphs in Fig. 6 indicate that low ratios of $\mathrm{C}_{1}^{\mathrm{MAX}} / \mathrm{C}_{1}^{\mathrm{eq}}$ are favored by (1) lower values of $\mathrm{t}_{1 / 2} / \mathrm{T}$, (2) high values of the ratio $\alpha / \beta$, and (3) high values of the ratio $\beta / \mathrm{k}_{\text {.1. }}$. If the drug is very "two compartment" (i.e., has a low value of $\beta / \mathrm{k}_{\mathrm{cl}}$ ), one should choose a value of $\mathrm{T}$ to provide a relatively low value of $t_{1 / 2} / T$; this is emphasized in the graph for $\beta / \mathrm{k}_{\mathrm{el}}=0.2$ in Fig. 6. If such a drug has a long half-life (small value of $\beta$ ) the value of $\alpha / \beta$ will usually in Fig. 6. If such a drug has a long half-life (small value of $\beta$ ) the value of $\alpha / \beta$ will usually be large, which together with the low value of $t_{1 / 2} / T$ will provide a reasonably low ratio of $\mathrm{C}_{1}^{\mathrm{MAx}} / \mathrm{C}_{1}^{\mathrm{eq}}$. 